\title{
The Liquid Phase Oxidation of Tetralin and p-Xylene in the Presence of Onium Salt Type Catalysts
}

\author{
Katsuyoshi Kanai**, Katsutoshi Ohkubo**, Hisao Kitano** \\ and Kenichi Fukui**
}

\begin{abstract}
Summary: In one of our early works, it was found that some onium salt type compounds exerted a strong catalytic effect on the oxidation of hydrocarbons. In the present work, the liquid phase oxidation of tetralin and p-xylene with oxygen was carried out in details in the presence of the onium salt type catalysts such as tetra-n-butylphosphonium, triphenylsulfonium, and tetraphenylphosphonium chlorides or bromides. By the use of these catalysts, tetralin was oxidized to tetralin hydroperoxide and p-xylene was converted to p-toluic acid and p-toluic aldehyde in mild conditions. The effect of triphenylsulfonium halides was more active than that of tetraphenylphosphonium halides and in particular the chlorides indicated an excellent ability in the oxidation.
\end{abstract}

\section{Introduction}

The catalyst in liquid phase oxidation of hydrocarbons with oxygen or air has widely been investigated from an industrial point of view.

In the low temperature liquid phase oxidation of hydrocarbons, transition metal compounds $^{1,2)}$ such as cobalt acetate, cobalt naphthenate, copper naphthenate, manganese acetate, and bromine compounds ${ }^{3}$ such as alkali bromides, hydrogen bromide and tetrabromoethane were generally used as catalysts. And for practical purpose, two or more of the compounds mentioned above were combined and the complexes or mixtures" were extensively used in petrochemical industry. Recently, Bredereck and coworkers ${ }^{5,6)}$ deconstrated some organic ammonium salts containing halogen anion were useful catalysts for some oxidation processes, and the application of ammonium salts was more effective to the reaction than alkali halides.

In our previous report ${ }^{7}$, catalytic activities of some onium salt type compounds containing nitrogen, sulfur and phosphorus atoms were tested by the liquid phase oxidation of tetralin with oxygen, and this indicated that

\footnotetext{
* Received December 10, 1964.

** Department of Fuel Chemistry, Faculty of Engineering, Kyoto University, Yoshida-Honmachi, Sakyo-ku, Kyoto, Japan.
}

they were better catalyst than Bredereck's ammonium catalysts. Sulfonium and phosphonium halides were stable crystalline compounds for storage and easily purified by recrystallization.

The oxygen absorption to tetralin and $p$ xylene was observed by reading the change of a mercury scale of an oxygen buret described in one of our previous reports ${ }^{7}$, which was cooperated with a mercury receptacle by an electrical method to keep an ordinary pressure of oxygen in reaction system. In the oxidation of tetralin, the effect of triphenylsulfonium chloride related to the reaction temperature. The oxygen absorption to tetralin was recognized already at about $30^{\circ} \mathrm{C}$ and the absorption velocity was observed to be ca. $4.74 \times 10^{-4}$ mole min. ${ }^{-1}$ at $50^{\circ} \mathrm{C}$, $5.40 \times 10^{-3}$ mole min..$^{-1}$ at $65^{\circ} \mathrm{C}$, and $1.36 \times 10^{-2}$ mole min..$^{-1}$ at $80^{\circ} \mathrm{C}$ after 10 minutes per one mole of tetralin employed. The absorption velocity for tetraphenylphosphonium chloride was found to be about $1.65 \times 10^{-3}$ mole min..$^{-1}$ at $65^{\circ} \mathrm{C}$ and $7.45 \times 10^{-3}$ mole min..$^{-1}$ at $80^{\circ} \mathrm{C}$ after 10 minutes per one mole of tetralin, respectively. In the reaction of tetralin, tetralin hydroperoxide was isolated by distillation as the main product of the reaction under reduced pressure.

In the experiment for xylene isomers, tetra- $n$-butylphosphonium chloride and tri- 
phenylsulfonium chloride were used as catalyst, and the susceptibility to oxidation of xylene isomers was in the following order: $o$-xylene $>p$-xylene $>m$-xylene and their reaction products consisted mainly of corresponding toluic aldehyde and toluic acid in all of the three cases.

In an attempt to screen useful catalysts for the oxidation of $p$-xylene, three groups of catalysts which were tetra- $n$-butylphosphonium (I), triphenylsulfonium (II) and tetraphenylphosphonium halides (III) containing chlorine and bromine anions were used.

$$
\left(n-\mathrm{C}_{4} \mathrm{H}_{9}\right)_{4} \mathrm{P}^{+} \mathrm{X}^{-} \quad\left(\mathrm{C}_{6} \mathrm{H}_{5}\right)_{3} \mathrm{~S}^{+} \mathrm{X}^{-} \quad\left(\mathrm{C}_{6} \mathrm{H}_{5}\right)_{4} \mathrm{P}^{+} \mathrm{X}^{-}
$$

These onium salts were almost insoluble to $p$-xylene, and the reaction started in a suspendeded state of catalysts, and then the amount of absorbed oxygen was measured continuously.

Tetra- $n$-butylphosphonium bromide had a stronger catalytic effect for the oxidation of $p$-xylene than the chloride. Triphenylsulfonium chloride also indicated an effective action. For instance, in the use of this compound, the oxygen absorption velocity to $p$-xylene at $110^{\circ} \mathrm{C}$ was $6.4 \times 10^{-5}$ mole min..$^{-1}$ after 30 minutes, $1.8 \times 10^{-4}$ mole min. ${ }^{-1}$ after 60 minutes and $4.80 \times 10^{-4}$ mole $\cdot \mathrm{min}^{-1}$ after 120 minutes, while, in the case of tetra- $n$ butylphosphonium bromide, the absorption velocity was $1.4 \times 10^{-4}$ mole min. ${ }^{-1}$ after 30 minutes, $\quad 2.7 \times 10^{-4}$ mole min. $^{-1}$ after 60 minutes, and $4.6 \times 10^{-4}$ after 120 minutes per one mole of $p$-xylene.

In the reaction catalysed by tetraphenylphosphonium halides, the induction period was longer in the case of chloride than that of the bromide. However, the chloride exhibited a more enduring catalytic ability than the bromide.

Ohta and Marumo ${ }^{1}$ reported the liquid phase oxidation of $p$-xylene catalysed by several transition metal naphthenates at $135^{\circ} \mathrm{C}$ for $4-10$ hours without polar solvent. The reaction condition and the yield of main products, $p$-toluic aldehyde and $p$-toluic acid, seemed to be similar to the present experiment using onium catalyst for $p$-xylene oxidation. In the oxidation of tetralin, however, our onium salt catalyst was found to give a better result.

From the above-mentioned observations, certain onium compounds containing phosphorus or sulfur atom and chlorine anion proved to be generally useful catalysts for low temperature reaction of hydrocarbons with oxygen. Similar results have also been obtained in the use of air instead of oxygen, which will be reported in future.

The catalytic activity of onium salts was generally in the following order: triphenyl sulfonium chloride $>$ tetra- $n$-butylphosphonium chloride tetraphenylphosphonium chloride and these onium catalysts could be recovered from a mixture reacted below $115^{\circ} \mathrm{C}$. The catalysts recovered were used repeatedly and behaved as effectively as the fresh onium compounds in subsequent oxidation reactions.

\section{Experimental}

\section{Apparatus}

The amount of absorbed oxygen during the reaction was measured by a modified apparatus described in the previous paper? The apparatus mainly consisted of an oxygen reservoir buret $(200 \mathrm{ml})$, a reaction vessel $(50 \mathrm{ml})$ and a mercury receptacle $(200 \mathrm{ml})$. The buret was surrounded by a water jacket to keep the temperature constant, the upper side of the buret was introduced to the reaction vessel through a manometer and the lower side was connected to the mercury receptacle. The buret and the mercury receptacle were operated simultaneously to maintain a constant pressure of oxygen by an electrical method. The reaction vessel fitted with a magnetic stirrer was automatically controlled to keep desired conditions. After the catalyst and the hydrocarbon were placed in the reaction vessel, oxygen was brought into the buret and the air in the reaction system was removed by moving the mercury receptacle up and down. When the air escaped completely, oxygen was charged into the buret and the reaction mixture was stirred magnetically. The amount of oxygen absorbed was measured.

\section{Materials}

Oxygen: Oxygen (J.P. grade) from a bomb was dried with sulfuric acid and silica gel, and the purity was minimum $99.0 \%$ by 
Table 1

\begin{tabular}{l|l|l|c}
\hline \multicolumn{1}{c|}{ Catalyst } & Chemical formula & \multicolumn{1}{c|}{ Appearance } & Melting point $\left({ }^{\circ} \mathrm{C}\right)$ \\
\hline Di- $n$-butylammonium chloride & $\left(n-\mathrm{C}_{4} \mathrm{H}_{8}\right)_{2} \mathrm{H}_{2} \mathrm{NCl}$ & Colorless crystals & $283-284$ \\
Tetra- $n$-butylphosphonium bromide & $\left(n-\mathrm{C}_{4} \mathrm{H}_{0}\right)_{4} \mathrm{PBr}$ & Colorless crystals & $112-113$ \\
Tetra- $n$-butylphosphonium chloride & $\left(n-\mathrm{C}_{4} \mathrm{H}_{8}\right)_{4} \mathrm{PCl}$ & Colorless crystals & $67-68$ \\
Tetraphenylphosphonium bromide & $\left(\mathrm{C}_{6} \mathrm{H}_{5}\right)_{4} \mathrm{PBr}$ & Colorless needles & $288-289$ \\
Tetraphenylphosphonium chloride & $\left(\mathrm{C}_{6} \mathrm{H}_{5}\right)_{4} \mathrm{PCl}$ & Colorless needles & $271-272$ \\
Triphenylsulfonium bromide & $\left(\mathrm{C}_{6} \mathrm{H}_{5}\right)_{3} \mathrm{SBr}$ & Colorless needles & $291-292$ \\
Triphenylsulfonium chloride & $\left(\mathrm{C}_{6} \mathrm{H}_{5}\right)_{3} \mathrm{SCl}$ & Colorless needles & $297-298$ \\
\hline
\end{tabular}

volume.

Tetralin: Commercial pure tetralin was shaken with concentrated sulfuric acid, neutralized with 10\% sodium hydroxide solution, washed with water, dried and distilled to afford pure tetralin (b.p. $206-207^{\circ} \mathrm{C}$ ).

$o$-Xylene and $m$-Xylene: Commercial pure xylenes were dried and rectified by the Podbielniak apparatus to give pure samples: 0 xylene boiled at $144.0-144.2^{\circ} \mathrm{C}\left(n_{\mathrm{n}}^{20} 1.5055\right)$ and $m$-xylene boiled at $139.0-139.1^{\circ} \mathrm{C}$ $\left(n_{\mathrm{D}}^{20}\right.$ 1.4972).

$p$-Xylene: $p$-Xylene $(98 \%)$ was washed repeatedly with concentrated sulfuric acid to give a colorless acid layer. The oil was washed with water, dried over anhydrous sodium carbonate and then fractionated through an efficient column. The fraction boiled at the range of $136-137^{\circ} \mathrm{C}$ was chilled to afford pure crystals of $p$-xylene (m.p. $13^{\circ} \mathrm{C}$, b.p. $138.1-138.2^{\circ} \mathrm{C}, n_{\mathrm{D}}^{20} 1.4958$ ).

Catalyst: Catalysts were prepared by our earlier method $^{7,8)}$, purified by recrystallization and their properties were listed in Table 1.

\section{Oxidation of tetralin}

In the reaction vessel were placed $10 \mathrm{ml}$ $(0.073 \mathrm{~mole})$ of tetralin and $10 \mathrm{mg}$ of onium salts listed in Table 1 as the catalyst. The reaction vessel was immersed in an oil bath kept at a desired temperature and the reaction started with vigorous stirring. The absorbed oxygen was measured continuously. The results were shown in Fig. 1.

\section{Tetralin hydroperoxide}

The reaction mixture in Experiment 3. was transfered into a distillation flask and unreacted tetralin was then distilled off under nitragen stream of diminished pressure below $4 \mathrm{mmHg}$. The residue was cooled to give crude tetralin hydroperoxide (slight yellowish needles m.p. $50-52^{\circ} \mathrm{C}$ ) and the crystals were

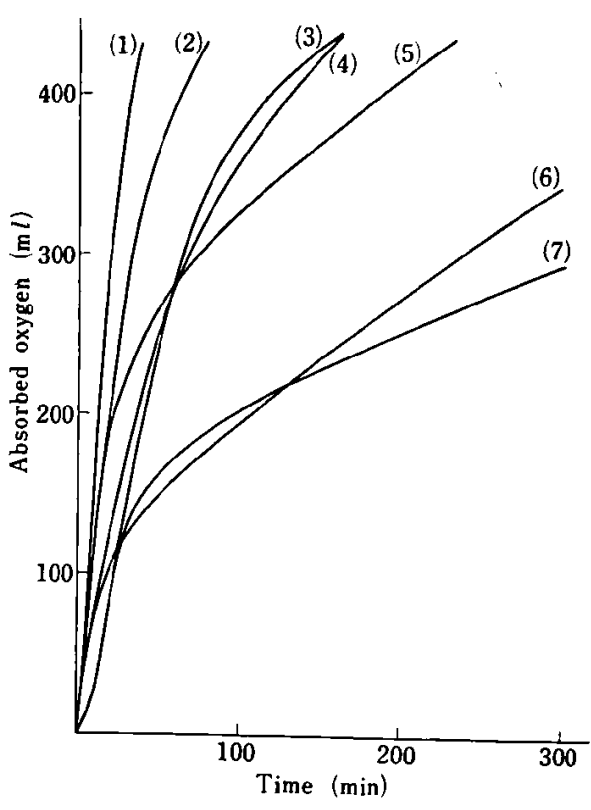

(1) Tetralin $10 \mathrm{ml}+\left(\mathrm{C}_{6} \mathrm{H}_{5}\right)_{3} \mathrm{SCl} 10 \mathrm{mg}$

(2) Tetralin $10 \mathrm{ml}+\left(\mathrm{C}_{6} \mathrm{H}_{5}\right)_{4} \mathrm{PCl} 10 \mathrm{mg}$

(3) Tetralin $10 \mathrm{~m} l+\left(n-\mathrm{C}_{4} \mathrm{H}_{9}\right)_{2} \mathrm{H}_{2} \mathrm{NCl} 10 \mathrm{mg}$

(4) Tetralin $10 \mathrm{ml}+\left(n-\mathrm{C}_{4} \mathrm{H}_{9}\right)_{4} \mathrm{PCl} 10 \mathrm{mg}$

(5) Tetralin $10 \mathrm{ml}+\left(\mathrm{C}_{6} \mathrm{H}_{5}\right)_{3} \mathrm{SBr} 10 \mathrm{mg}$

(6) Tetralin $10 \mathrm{ml}+\left(n-\mathrm{C}_{4} \mathrm{H}_{9}\right)_{4} \mathrm{PBr} 10 \mathrm{mg}$

(7) Tetralin $10 \mathrm{ml}+\left(\mathrm{C}_{6} \mathrm{H}_{5}\right)_{4} \mathrm{PBr} 10 \mathrm{mg}$

Fig. 1 Oxidation of tetralin at $80^{\circ} \mathrm{C}$

Table 2

\begin{tabular}{l|c|c|c|c}
\hline \multicolumn{1}{c|}{ Catalyst } & $\begin{array}{c}\text { Reaction } \\
\text { Time } \\
(\text { min. })\end{array}$ & $\begin{array}{c}\text { Temp. } \\
\left({ }^{\circ} \mathrm{C}\right)\end{array}$ & $\begin{array}{c}\text { Oxygen } \\
(\text { ml })\end{array}$ & $\begin{array}{c}\text { Yields of } \\
\text { tetralin } \\
\text { hydroperoxide } \\
(\%)\end{array}$ \\
\cline { 1 - 2 }$-\cdots$ & 360 & 80 & 595 & 64 \\
$\left(\mathrm{C}_{6} \mathrm{H}_{5}\right)_{4} \mathrm{PCl}$ & 360 & 80 & 319 & 64 \\
$\left(\mathrm{C}_{6} \mathrm{H}_{5}\right)_{4} \mathrm{PBr}$ & 319 & 62 \\
$\left(n-\mathrm{C}_{4} \mathrm{H}_{9}\right)_{4} \mathrm{PCl}$ & 360 & 80 & 546 & 62 \\
$\left(n-\mathrm{C}_{4} \mathrm{H}_{\theta}\right)_{4} \mathrm{PBr}$ & 360 & 80 & 384 & 58.5 \\
$\left(\mathrm{C}_{6} \mathrm{H}_{5}\right)_{8} \mathrm{SCl}$ & 360 & 80 & 612 & 71.5 \\
$\left(\mathrm{C}_{6} \mathrm{H}_{5}\right)_{3} \mathrm{SBr}$ & 360 & 80 & 582 & 63 \\
\hline
\end{tabular}

recrystallized from toluene to give pure sample melting at $54^{\circ} \mathrm{C}$, which was identified as an authentic specimen. The results were listed in Table 2.

5. Oxidation of xylene isomers

In the reaction vessel $10 \mathrm{ml}(0.080$ mole $)$ 


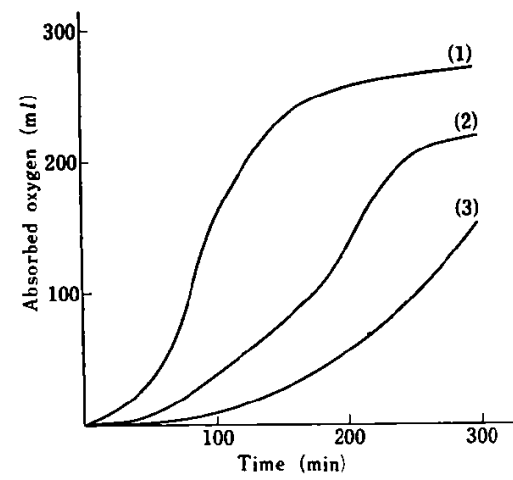

(1) $o$-Xylene $10 \mathrm{ml}+\left(\mathrm{C}_{6} \mathrm{H}_{5}\right)_{3} \mathrm{SCl} 70 \mathrm{mg}$

(2) $p$-Xylene $10 \mathrm{ml}+\left(\mathrm{C}_{6} \mathrm{H}_{5}\right)_{3} \mathrm{SCl} 70 \mathrm{mg}$

(3) $m$-Xylene $10 \mathrm{ml}+\left(\mathrm{C}_{6} \mathrm{H}_{5}\right)_{3} \mathrm{SCl} 70 \mathrm{mg}$

Fig. 2 Oxidation of xylene isomers in the presence of triphenyl sulfonium chloride at $110^{\circ} \mathrm{C}$

of xylene and $90 \mathrm{mg}$ of triphenylsulfonium chloride as the catalyst were placed and the reaction vessel was heated at $110^{\circ} \mathrm{C}$. The results were shown in Fig. 2. After the reaction mixture was cooled and then treated with cold anhydrous ether to form white mass, the precipitates were collected by filtration, washed with ether and dried. The recovered materials were found to be unchanged catalyst. The recovered catalysts could be

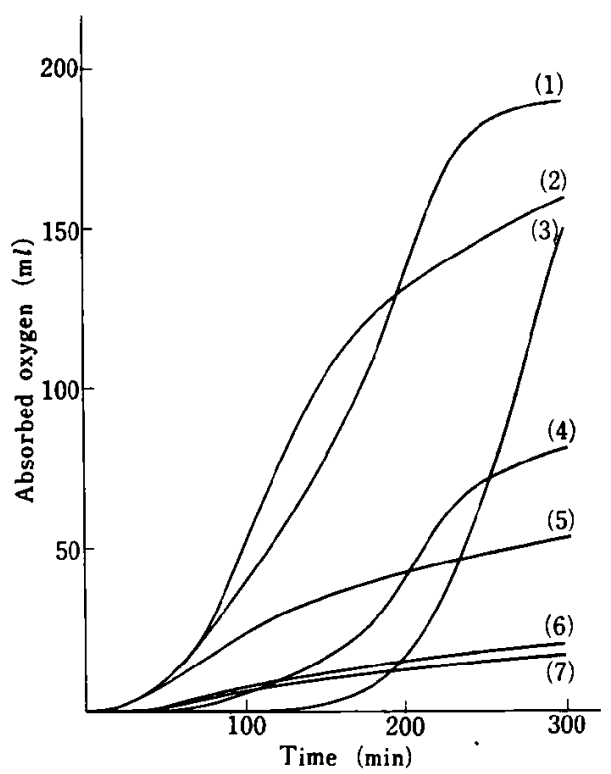

(1) $p$-Xylene $10 \mathrm{ml}+\left(\mathrm{C}_{6} \mathrm{H}_{3}\right)_{3} \mathrm{SCl} 50 \mathrm{mg}$

(2) $p$-Xylene $10 \mathrm{ml}+\left(n-\mathrm{C}_{4} \mathrm{H}_{9}\right)_{4} \mathrm{PBr} 50 \mathrm{mg}$

(3) $p$-Xylene $10 \mathrm{ml}+\left(n-\mathrm{C}_{4} \mathrm{H}_{8}\right)_{4} \mathrm{PCl} 50 \mathrm{mg}$

(4) $p$-Xylene $10 \mathrm{ml}+\left(n-\mathrm{C}_{4} \mathrm{H}_{9}\right)_{2} \mathrm{H}_{2} \mathrm{NCl} 50 \mathrm{mg}$

(5) $p$-Xylene $10 \mathrm{ml}+\left(\mathrm{C}_{6} \mathrm{H}_{5}\right)_{3} \mathrm{SBr} 50 \mathrm{mg}$

(6) $p$-Xylene $10 \mathrm{ml}+\left(\mathrm{C}_{6} \mathrm{H}_{5}\right)_{4} \mathrm{PCl} 50 \mathrm{mg}$

(7) $p$-Xylene $10 \mathrm{ml}+\left(\mathrm{C}_{6} \mathrm{H}_{5}\right)_{4} \mathrm{PBr} 50 \mathrm{mg}$

Fig. 3 Influence of onium salts in $p$-xylene oxidation at $110^{\circ} \mathrm{C}$ employed to further oxidation experiments as well as newly prepared catalysts.

6. Influence of the composition of onium salts in $p$-xylene oxidation

$10 \mathrm{ml}(0.080$ mole $)$ of $p$-xylene was placed in the reaction vessel and $50 \mathrm{mg}$ of onium salt shown in Fig. 3 was added as the catalyst. Reactions were greatly influenced by the composition of onium salts indicated in Fig. 3.

7. The amount of triphenylsulfonium chloride in p-xylene oxidation

The oxidation of $p$-xylene with oxygen in the presence of triphenylsulfonium chloride was also carried out similarly to Experiment 6. The amount of the catalyst used was changed from $10 \mathrm{mg}$ to $90 \mathrm{mg}$ for $10 \mathrm{ml}$ of $p$-xylene. The results were shown in Fig. 4.

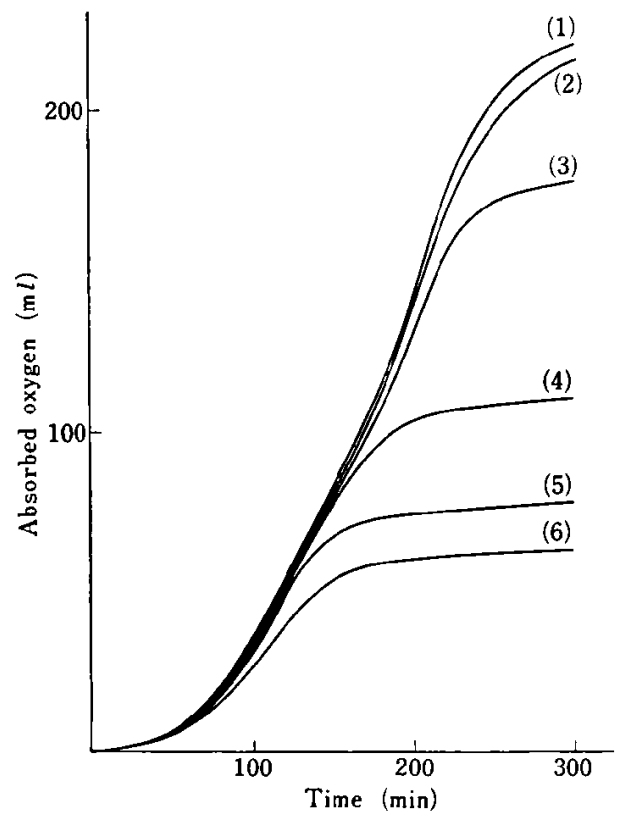

$p$-Xylene $10 \mathrm{mg}+\left(\mathrm{C}_{6} \mathrm{H}_{5}\right)_{3} \mathrm{SCl}:$ (1) $90 \mathrm{mg}$, (2) $80 \mathrm{mg}$,

(3) $50 \mathrm{mg}$, (4) $30 \mathrm{mg}$, (5) $20 \mathrm{mg}$, (6) $10 \mathrm{mg}$

Fig. 4 Oxidation of $p$-xylene catalyzed by triphenylsulfonium chloride at $110^{\circ} \mathrm{C}$

The oxygen absorption curve versus reaction time at each experiment was of definite characteristic shape and the total amount of oxygen in the reaction was paralleled with that of the catalyst employed, but a recommendable amount was more than $50 \mathrm{mg}$ with respect to triphenylsulfonium chloride for $10 \mathrm{ml}$ of $p$-xylene.

8. Oxidation temperature of $p$-xylene

In the oxidation of tetralin (Experiment 
3 ), the reaction was carried out at $50-80^{\circ} \mathrm{C}$ to collect tetralin hydroperoxide, but the separation of pure $p$-xylene hydroperoxide was rather difficult in the oxidation of $p$ xylene carried out at $100-130^{\circ} \mathrm{C}$. In the reaction vessel, $10 \mathrm{ml}$ of $p$-xylene and $90 \mathrm{mg}$ of triphenylsulfonium chloride were placed and the reaction vessel was immersed into an oil bath maintained at a desired temperature. The oxygen absorption was continuously measured and the results were shown in Fig. 5.

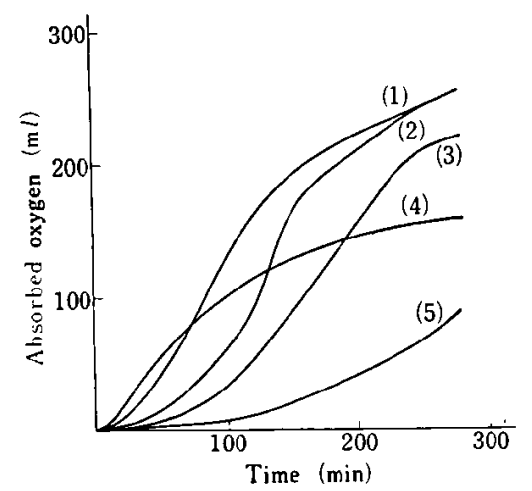

$p$-Xylene $10 \mathrm{ml}+\left(\mathrm{C}_{6} \mathrm{H}_{5}\right)_{3} \mathrm{SCl} 90 \mathrm{mg}$ : (1) at $120^{\circ} \mathrm{C}$,
(2) at $115^{\circ} \mathrm{C}$,
(3) at $110^{\circ} \mathrm{C}$,
(4) at $130^{\circ} \mathrm{C}$,

(5) at $100^{\circ} \mathrm{C}$

Fig. 5 Effect of temperature on $p$-xylene oxidation

The $p$-xylene oxidation without polar solvent was not rapid at $100^{\circ} \mathrm{C}$, but remarkably rapid at $115-120^{\circ} \mathrm{C}$. The reaction at $130^{\circ} \mathrm{C}$ showed a very short induction period and a decreasing of catalytic ability. Although triphenylsulfonium chloride was so stable on heating below its melting point, $297-298^{\circ} \mathrm{C}$, that the catalyst remained unchangable in boiling $p$-xylene in the absence of oxygen, the catalytic action was slowly depressed during the reaction.

9. Products of p-xylene oxidation

To the reaction mixture was added $5 \mathrm{ml}$ of 1-N sodium hydroxide solution and the mixture was titrated with $0.1-\mathrm{N}$ hydrochloric acid to measure the amount of toluic acid. The resultant solution was mixed with $50 \mathrm{ml}$ of ethyl alcohol and $100 \mathrm{ml}$ of 2,4-dinitrophenylhydrazonium sulfate solution (2,4-DNPH $\left.40 \mathrm{~g}+\mathrm{H}_{2} \mathrm{SO}_{4} 200 \mathrm{ml}+\mathrm{H}_{2} \mathrm{O} 300 \mathrm{ml}+\mathrm{C}_{2} \mathrm{H}_{5} \mathrm{OH} 1 l\right)$. The mixture was shaked for several hours to precipitate an orange red hydrazone. The precipitate was filtered, washed with $10 \mathrm{ml}$ of $\mathbf{5 0} \%$ aq. alcohol and dried in vacuum to weigh the hydrazone. The acidic substance from the oxidation mixture was found to be the almost pure $p$-toluic acid. The hydrazone recrystallized from nitrobenzene was identified to be that of $p$-toluic aldehyde with authentic specimen, which melted at $234.0^{\circ}-234.5^{\circ} \mathrm{C}$. Some examples of the oxidation of $p$-xylene $(10 \mathrm{ml})$ catalysed by triphenylsulfonium chloride at several reaction conditions were listed in Table 3.

Table 3 Oxidation products of $p$-xylene*

\begin{tabular}{|c|c|c|c|c|c|}
\hline \multirow{2}{*}{$\begin{array}{c}\text { Catalyst } \\
\left(\mathrm{C}_{6} \mathbf{H}_{5}\right)_{s} \mathrm{SCl} \\
(\mathrm{mg})\end{array}$} & \multicolumn{2}{|c|}{ Reaction } & \multirow{2}{*}{\begin{tabular}{|c|} 
The \\
amount of \\
absorbed \\
oxygen \\
(mole)
\end{tabular}} & \multicolumn{2}{|c|}{ Products } \\
\hline & Temp. & $\begin{array}{l}\text { Time } \\
(\min .)\end{array}$ & & $\begin{array}{l}\text { Toluic } \\
\text { acid } \\
\text { (mole) }\end{array}$ & $\begin{array}{c}\text { Toluic ** } \\
\text { aldehyde } \\
\text { (mole) }\end{array}$ \\
\hline 10 & 110 & 190 & 0.0025 & 0.00065 & 0.00097 \\
\hline 20 & 110 & 190 & 0.0031 & 0.00084 & 0.00114 \\
\hline 30 & 110 & 210 & 0.0043 & 0.00130 & 0.00150 \\
\hline 40 & 110 & 240 & 0.0071 & 0.00258 & 0.00200 \\
\hline 50 & 110 & 260 & 0.0081 & 0.00321 & 0.00214 \\
\hline 80 & 110 & 300 & 0.0088 & 0.00362 & 0.00244 \\
\hline 90 & 110 & 300 & 0.0100 & 0.00451 & 0.00251 \\
\hline 10 & 115 & 180 & 0.0029 & 0.00073 & 0.00119 \\
\hline 20 & 115 & 190 & 0.0051 & 0.00146 & 0.00186 \\
\hline 50 & 115 & 190 & 0.0074 & 0.00262 & 0.00238 \\
\hline 90 & 115 & 280 & 0.0105 & 0.00443 & 0.00283 \\
\hline 10 & 120 & 110 & 0.0029 & 0.00071 & 0.00082 \\
\hline 20 & 120 & 160 & 0.0046 & 0.00127 & 0.00121 \\
\hline 40 & 120 & 200 & 0.0075 & 0.00252 & 0.00197 \\
\hline 90 & 120 & 310 & 0.0105 & 0.00430 & 0.00244 \\
\hline 10 & 130 & 140 & 0.0035 & 0.00089 & 0.00115 \\
\hline 30 & 130 & 150 & 0.0042 & 0.00108 & 0.00133 \\
\hline 50 & 130 & 200 & 0.0050 & 0.00164 & 0.00174 \\
\hline 70 & 130 & 200 & 0.0053 & 0.00174 & 0.00181 \\
\hline 90 & 130 & 230 & 0.0062 & 0.00193 & 0.00205 \\
\hline
\end{tabular}

\section{Discussion}

In the present work the low temperature liquid phase oxidation of tetralin with oxygen in the presence of onium salt catalysts exhibited the typical characteristics of an autoxidation process, and the observation was confirmed by comparing the yields of tetralin hydroperoxide in the use of several catalysts indicated in Table 2 . The oxygen was absorbed by tetralin without induction period and triphenylsulfonium and tetraphenylphosphonium chlorides showed a superior catalytic behavior.

The action of onium salt catalysts appeared 
to depend on both of the cationic part and the halogen anion. The effect of onium chloride was noteworthy, notwithstanding the order (iodine $>$ bromine $>$ chlorine) of the easiness of halogen radical formation from halides in the presence of oxygen ${ }^{7}$. The difference in activity of these catalysts might be caused by their heat stability and solubility to the reaction mixture of oxidation products such as hydroperoxide and other by products, and also by the easiness of abstraction of a hydrogen atom in the hydrocarbon molecule by the halogen radical preformed.

In the liquid phase oxidation of xylene isomers, $m$-xylene had a short induction period (about $20 \mathrm{~min}$.) for oxygen absorption shown in Fig. 2, and 0 -xylene absorbed the oxygen rapidly to form $o$-toluic acid and aldehyde as main products. After the oxidation of xylene isomers was carried out at $110^{\circ} \mathrm{C}$, the catalyst was collected, identified by ultraviolet spectroscopy with the initial triphenylsulfonium chloride and repeatedly employed for the same purpose, indicating a similar catalytic effect to the second batch of reaction.

The catalyst used in the reaction above $130^{\circ} \mathrm{C}$ was gradually decomposed during the reaction, and it was unsuccessful to recover it. The decomposition of the catalyst became appreciable at the boiling points of xylene isomers. Triphenylsulfonium chloride in Fig. 3 , showed an excellent effect as much as that of the oxidation of tetralin in Fig. 1, and two curves with respect to tetra- $n$-butylphosphonium chloride and bromide crossed over $300 \mathrm{~min}$. In this experiment (Fig. 3) tetraphenylphosphonium chloride was expected to give a good result but the chloride had little effect for reason of its unstable property on heating in the reaction medium of $p$-xylene. Tetraphenylphosphonium halides underwent decomposition accompanied by a color change in the oxidation mixture at $110^{\circ} \mathrm{C}$ to form triphenylphosphine oxide and phenolic materials owing to the decomposition of $p$-xylene hydroperoxide as an initial oxidation product.

From the Experiment 6, the effect of the amount of triphenylsulfonium chloride on $p$ xylene oxidation was examined in Fig. 4. The increase in the volume of absorbed oxygen reached the limit at the amount of $80-90 \mathrm{mg}$ of the chloride employed to $10 \mathrm{ml}$ of $p$-xylene. The total amount of oxygen in Fig. 4 appeared to be proportional to $2 / 3$ rd power of the amount of triphenylsulfonium chloride catalyst and this relation was shown in Fig. 6 .

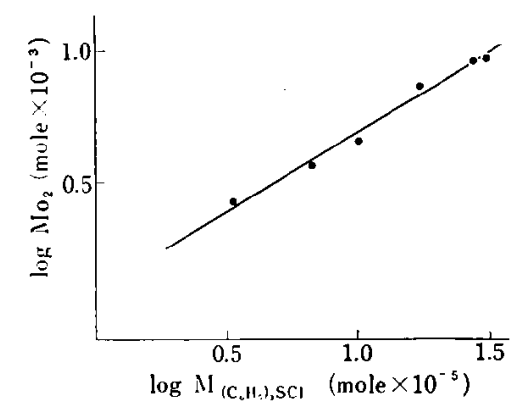

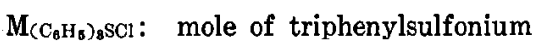
$\mathrm{MO}_{2}$ : mole of total absorbed oxygen

Fig. 6 Relation of the amount of triphenylsulfonium chloride to the total amount of absorbed oxygen in $p$-xylene oxidation at $110^{\circ} \mathrm{C}$

In Experiment 8, the increase of oxygen absorption at the initial reaction step was ascribed to an increase of reaction temperature. However, the best result was obtained in $115-120^{\circ} \mathrm{C}$ because the triphenylsulfonium chloride partially decomposed at $130^{\circ} \mathrm{C}$ through the reaction (Fig. 5). These observations suggested the necessity of a careful selection of reaction conditions such as the catalyst amount and the reaction temperature in the liquid phase oxidation of $p$-xylene catalysed by triphenylsulfonium chloride.

The formation of $p$-toluic acid at $110-130^{\circ} \mathrm{C}$ was greatly influenced by the amount of the absorbed oxygen but that of $p$-toluic aldehyde was not so affected. The relation of the amount of $p$-toluic acid determined in Experiment 9. against the total amount of oxygen absorbed appeared to be proportional to a three-second order in Table 3.

Further experiments of other alkyl benzenes such as cumene or $p$-cymene in the liquid phase oxidation, catalysed by triphenylfulfonium chloride below $95^{\circ} \mathrm{C}$ indicated similar tendency of oxygen absorption as in the case of $p$-xylene oxidation.

\section{Conclusion}

The liquid phase oxidation of tetralin and $p$-xylene with oxygen under ordinary pressure was carried out in the presence of onium 
salts as new catalysts. The main catalysts were tetra- $n$-butylphosphonium, triphenylphosphonium, triphenylsulfonium and tetraphenylphosphonium chlorides and bromides. Tetralin was smoothly oxidized by these catalysts to afford tetralin hydroperoxide. In the oxidation of $p$-xylene, the oxygen absorption was greatly affected by the composition, the amount of catalysts, and the reaction temperature. The main products of $p$-xylene oxidation were $p$-toluic acid and $p$ toluic aldehyde and the best result was obtained by the use of triphenylsulfonium chloride as the catalyst. Catalytic activities of onium compounds showed generally in the following order: sulfonium chloride $>$ phosphonium chloride $>$ ammonium chloride. The onium salt catalysts were prepared easily and their activities did not decrease on storage for a long period of time. In the field of liquid phase oxidation studies, attention for an effective catalyst has been centered in the petrochemical industry and further interesting developments are expected.

\section{References}

1) Ohta, N., Marumo, S., J. Chem. Soc. Japan, Ind. Chem. Sec., 58, 798 (1955).

2) Robertson, A., Walters, W.A., Trans. Faraday Soc., 42, 201 (1946); George, P., Robertson, A., Trans. Faraday Soc., 42, 217 (1946); Bowden, C. H., Brit. 623,836 (1949); Mark, L. F., Ind. Eng. Chem., 42, 1718 (1949); Muller, E. R., Ind. Eng. Chem., 46, 562 (1954); Toland, W. H., Nimer, E. L., Paper presented before the 4th World Petroleum Congress, Section IV/B Reprint 1 (1955); Sharp, J.A., J. Chem. Soc., 1957, 2026.

3) Vaughan, W. E., Rust, F. F., U. S. 2,369, 182 (1945); $2,395,523$ (1946); 2,446,797 (1948); 2,449,349 (1948); Barnet, B., Bell, E. R., Dickey, F. H., Rust, F. F., Vaughan, W. E., Ind. End. Chem., 41, 2612 (1949); Rust, F. F., Vaughan, W. E., Ind. Eng. Chem., 41, 2595 (1949); Toland, W. G., Ind. Eng. Chem., 50, 1386 (1958).

4) Saffer, A., Barker, R. S., Belg. P. 546,191 (1955); U. S. 2,833,816 (1958); Japan P. 1959-2,662; Revens, D. A., Trans. Faraday Soc., 55, 1768 (1958); Sigeyasu, M., J.Chem. Soc. Japan, Ind. Chem. Sec., 67, 1396 (1964).

5) Bredereck, H., Wagner, A., Kottenhahn, K. G., Kottenhahn, A., Blascke, R., Angew. Chem., 70, 503 (1958).

6) Bredereck, H., Wagner, A., Blascke, R., Demetriades, C., Kottenhahn, K. G., Chem. Ber., 92, 2628 (1959).

7) Fukui, K., Kanai, K., Takezono, T., Kitano, H., J. Chem. Soc. Japan, Ind. Chem. Sec., 67, 1131 (1964).

8) Fukui, K., Kanai, K., Kitano, H., J. Chem. Soc. Japan, Pure Chem. Sec., 82, 178 (1961). 